\title{
A Three-Sector Spatial Growth Model of a Small Open Economy with Capital Accumulation
}

\author{
Wei-Bin Zhang \\ Ritsumeikan Asia Pacific University
}

\begin{abstract}
This paper presents a growth model of a small open economy with economic geography. The economy has three - industrial, services and housing - sectors. The economy is located along a line segment and land is for residential use. The model synthesizes the four well-known models in neoclassical growth theory and urban economics - the Solow growth model, Uzawa's two-sector model, the Alonso urban model, and the Muth housing model - in the context of a small open economy. We analyze the dynamics of a spatial economy and simulate the model over time and space. We show how changes in some parameters, such as the rate of interest and domestic preference, can affect economic structures and land use of the small economy. For instance, the simulation results show that as the rate of interest is increased in the global market, the domestic wage rate, the output levels per worker of the industrial and service sectors, the capital intensities of the three sectors, the capital employed by the three sectors, the national output are reduced, the price of services, the consumption levels of goods, services and housing, the wealth per capita are increased. The labor employment of the industrial sector is reduced and the labor employment of service sector is increased. The housing rent is increased and the land rent is reduced due to the rise in the rate of interest.
\end{abstract}

\footnotetext{
*Corresponding address: Wei-Bin Zhang: Ritsumeikan Asia Pacific University, Jumonjibaru, Beppu-Shi, Oita-ken, 874-8577, Japan, Tel: 0977-78-1020, Fax: 0977-78-1123, e-mail: wbz1@apu.ac.jp. 
- JEL Classification : R11, R14

- Key Words: small open economy, economic growth, residential distribution, Solow-Uzawa's growth model, Alonso's urban model, Muth's housing model

\section{Introduction}

There are close interactions between economic development and economic geography. Economic growth, for instance, encourages demand for housing and affects prices and availability of land for housing. On the other hand, changes in the housing market will affect economic growth. For instance, as demand for housing is increased, demands for different services and goods and prices for different services and goods will be affected. Nevertheless, there are few economic models which deal with the interdependence with micro-behavioral foundation, though the study of the economic growth with housing and economic geography has increasingly caused attention in urban economics and regional science. Yet, urban economics has not succeeded in explaining spatial evolution and growth with capital accumulation. As pointed out by Baldwin and Martin (2004: 2675-6), "Many of the most popular economic geography models focus on labor. ... These are unsuited to the study of growth." Capital accumulation is seldom modeled with land use pattern and land markets in the literature of urban economics. Fujita and Thisse (2002: 389) state the current situations of spatial economic growth as follows: "Clearly, space and time are intrinsically mixed in the process of economic development. However, the study of their interaction is a formidable task. ... Not surprisingly, therefore, the field is still in its infancy, and relevant contributions have been few." This study attempts to make a contribution to solving the long standing puzzle of modeling economic growth with space by developing an economic growth model with economic geography, basing on the four key models in the neoclassical growth theory and new urban economics within the context of growth theory of small open economies. The four models are the Solow growth model and Uzawa two-sector growth model in the neoclassical growth theory and the Alonso urban model and Muth housing model in the new

\footnotetext{
${ }^{1}$ As reviewed by Zhang (2008a), there are many spatial models built on microeconomic foundation in the recent literature of the new economic geography. However, almost all these models are static and neglect capital accumulation. We refer the comprehensive surveys on the literature to Leung (2004), Henderson and Thisse (2004) and Capello and Nijkamp (2004) for the literature of the new economic geography.
} 
urban economics.

Most of the models in the neoclassical growth theory model are extensions and generalizations of the pioneering works of Solow. The model has played an important role in the development of economic growth theory by using the neoclassical production function and neoclassical production theory. The Solow model has been extended and generalized in numerous directions. An important extension was initiated by Uzawa (1961), who made an extension of Solow's onesector economy by a breakdown of the productive system into two sectors using capital and labor, one of which produces industrial goods, the other consumption goods. Solow's one-sector growth model, Uzawa's two-sector growth model, and their various extensions and generalizations are fundamental for the development of new economic growth theories as well. ${ }^{2}$ But all these studies do not have spatial dimension. The neoclassical growth theory has not bee extended to spatial economics. It should be noted that there are many economic models which deal with growth and capital accumulation within the analytical framework of small open economies. ${ }^{3}$ Nevertheless, this analytical framework has not been extended to spatial economics with land use and housing market. As argued by Lucas (1988), it is necessary to analyze urban configuration and economic growth as a connected whole. Partial equilibrium models fail to explain interactions among various sectors of economic activities over time and space. Although some attempts have been to apply neoclassical growth theory to address urban growth issues, these models do not take account of land and housing markets. ${ }^{4}$ It is obvious that an urban growth theory should take account of land and housing markets and economic geography.

Numerous contributions to urban economics have followed the equilibrium theory of urban land market pioneered by Alonso (1964). This approach has been extended in many directions. The earlier important contributions are made by Muth (1969), Mills (1967), Beckmann (1969), Solow (1973), and others. There are many contributions in the literature in the last two decades. However, most of the urban land-use models concentrate on the residential location and urban structure and neglect production aspects of urban dynamics. As most of these models are static,

\footnotetext{
${ }^{2}$ See, for instance, Diamond (1965), Stiglitz (1967), Benhabib et al (2000), Drugeon and Venditti (2001). ${ }^{3}$ Refer to, for instance, Obstfeld and Rogoff (1996), Lane (2001), Kollmann (2001, 2002), Benigno and Benigno (2003), and Gali and Monacelli (2005), for the literature on economics of open economies. ${ }^{4}$ Extending neoclassical growth theory to spatial economics is made by, for instance, Richardson (1977), Rabenau (1979), Henderson (1985), and Henderson et al (1995).
} 
they fail to take account of saving behavior and effects of wealth accumulation on economic geography. Another important issue in urban economics is housing market and its dynamics. A proper analysis of housing market requires an explicit treatment of space. Housing is the largest component of nonhuman wealth for households and housing services are a fundamental component of the household consumption. Housing is closely related to the rest of economy. For instance, in the United States, real estate investment account for over $50 \%$ of total private investment and real estate assets represent just under $60 \%$ of the nation's wealth. Almost $70 \%$ of U.S. real estate is residential. ${ }^{5}$ Housing has a set of intrinsic properties, which make it significantly from any other goods. In the last three decades, many studies have been carried out to analyze durable housing in spatial context. ${ }^{6}$ Nevertheless, as argued by Brito and Pereira (2002), the link between the housing market and long-term growth has been neglected in the literature. It is important to develop a growth model with housing market on microeconomic foundation.

This study is to explain spatial economic dynamics with interdependence of goods production, the residential land use pattern, wealth accumulation, housing rent, land rent over time and space, basing on the neoclassical growth theory and new urban economics. The economic principles of the two separated analytical frameworks in the growth theory and urban economics will be integrated into a compact theoretical framework through an alternative utility function proposed by Zhang (2005). The paper is a synthesis of the small-open economic growth model and the urban model proposed by Zhang (1994, 2007). Zhang (1994) proposed a spatial model of a closed national economy. The economy is not affected by global markets and the urban structure is simpler than this model. The previous study is only concerned with steady states, while this model explicitly analyzes the dynamics and simulates the model to illustrate how the system moves over time and space. This paper differs from Zhang (2007) in that the previous study studies an interregional open economy but with only one production sector, while this model examines the economic dynamics with three production sectors.

The paper is organized as follows. Section II defines the basic model. Section III shows how we solve the dynamics with economic geography and examine how some variables change over space. Section IV examines the equilibrium of the

\footnotetext{
${ }^{5}$ see, DiPasquale and Wheaton (1996).

${ }^{6}$ Refer to, for instance, Muth (1973), Anas (1978), Hockman and Pines (1980), Brueckner (1981), Arnott (1987), Brueckner and Pereira (1994), Arnott et al. (1999), and Braid (2001).
} 
spatial economy when the production functions of the industrial and services sectors are specified in the Cobb-Douglas form. Section V simulates the motion of the system with the Cobb-Douglas functions. Section VI examines effects of changes in some parameters on the economic geography over time. Section VII concludes the study. The appendix proves the main results in Section III.

\section{The Model}

This section defines a small open spatial growth model with capital accumulation and residential location. The model is a combination of the basic features of the four key models, the Solow growth model, the Uzawa two-sector growth model, the Alonso urban model, and the Muth housing model in the neoclassical growth theory, urban economics in the context of a small open economy. An open economy can import goods and services and borrow resources from the rest of the world or exports goods and services and lend resources abroad. There is a single good, called industrial good, in the world economy and the price of the industrial good is unity. ${ }^{7}$ We assume that the economy is too small to affect the world interest rate. The households hold wealth and land and receive income from wages, land rent, and interest payments of wealth. Land is only for residential use. Technologies of all the production sectors are characterized of constant returns to scale. All markets are perfectly competitive and capital and labor are completely mobile among the domestic sectors. Capital is perfectly mobile in international market and we neglect possibility of emigration or/and immigration.

The economy has three - industrial, services, and housing - sectors. ${ }^{8}$ The industrial sector produces industrial goods, which are freely traded in international market. It is a capital commodity used both for investment and consumption. The services sector produces services, which is used only for domestic consumption. The housing sector provides location-dependent housing services and can be

\footnotetext{
${ }^{7} \mathrm{An}$ important extension of the neoclassical model is to introduce money and exchange rate to the model. For the literature of a small open economy with money, see, for instance, Obstfeld and Rogoff (1996), and Gali and Monacelli (2005). Zhang (2008b) extensively examines different monetary growth models. It should be noted that Zhang (2008b) also applies the utility function accepted in this study to develop a comprehensive monetary growth theory mainly for national economies.

${ }^{8}$ The classification of the economic sectors is similar to that in a growth model of a small open economy by Brock (1988), in which goods and services are divided into traded and non-traded. Brock examines the dynamic adjustment of the relative price of non-traded and the current account following exogenous shocks, such as government purchases, changes in tax income or investment subsidy.
} 
consumed domestically. As far as urban structures are concerned, we follow the standard residential land-use model. The basic features of this model are that a city state is built on a flat featureless plain. All residents in the economy work in the CBD. People travel only between their homes and the CBD. Travel is equally costly in terms of time or/and money in all directions. An individual may reside at only one location. The only spatial characteristic of any location that directly matters is the distance from the CBD. The population is homogenous. The households achieve the same utility level regardless of where they locate. All the markets are perfectly competitive. The system is geographically linear and consists of two parts - the CBD and the residential area. The economy consists of a finite strip (of fixed length, $L$ ) of land extending from the CBD with constant unit width. We assume that the industrial and service sectors are concentrated in the CBD. The households occupy the residential area. We assume that the CBD is located at the left-side end of the linear territory, as illustrated in Figure 1, where $\omega$ denotes the distance from the CBD to a point in the residential area. As we will get the same conclusions if we locate the CBD at the center of the linear system, the specified urban configuration will not affect our discussion.

We assume that labor force, $N$, is homogeneous and is fixed. There is only one malleable industrial goods, which can be used as an input in three sectors in the economy. Capital depreciates at a constant exponential rate, $\delta_{k}$, which is independent of the manner of use. In addition to the industrial and service sectors, indexed respectively by $i$ and $s$, we introduce housing sector to the growth model. The housing production is similar to that in the Muth model. We assume that the total labor force is fully employed by the capital and service sectors. We select industrial goods to serve as numeraire.

Figure 1. The Spatial Configuration

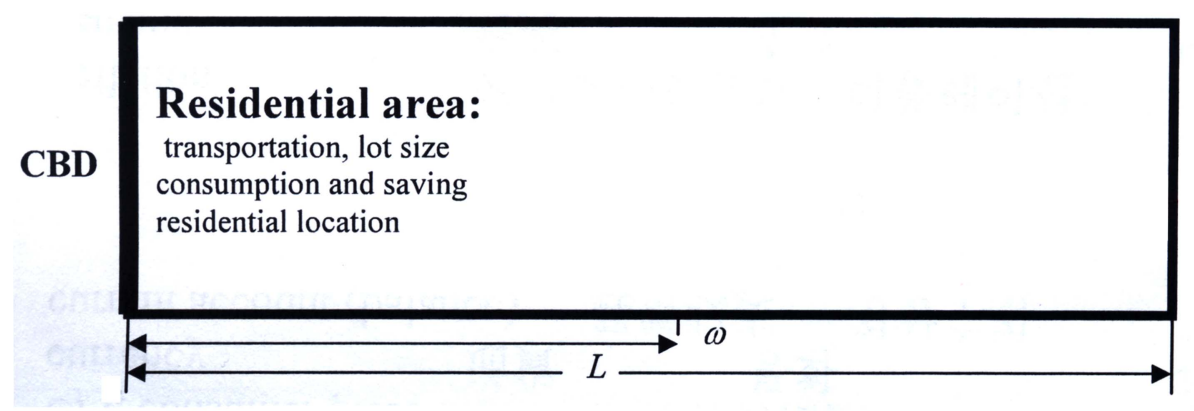


The industrial and service sectors use a single grade of labor and a single type of capital good. Both sectors use neoclassical technology with the standard Inada conditions. The production functions are given by $F_{j}\left(K_{j}(t), N_{j}(t)\right)$, where $F_{j}(t)$ is the output level of sector $j$ and $N_{j}(t)$ and are respectively the capital stocks and labor force employed by sector $j, j=i$, s. We have

$$
f_{j}(t)=f_{j}\left(k_{j}(t)\right), \quad f_{j}(t) \equiv \frac{F_{j}(t)}{N_{j}(t)}, \quad k_{j}(t) \equiv \frac{K_{j}(t)}{N_{j}(t)}, \quad j=i, s
$$

The function, $f_{j}$, has the following properties: (i) $f_{j}(0)=0$; (ii) $f_{j}$ is increasing, strictly concave on $R^{+}$and $C^{2}$ on $R^{++} ; f_{j}^{\prime}\left(k_{j}\right)>0$ and $f_{j}^{\prime \prime}(k)<0$ and (iii) $\lim _{k \rightarrow 0} f_{j}^{\prime}\left(k_{j}\right)=\infty$ and $\lim _{k \rightarrow+\infty} f_{j}^{\prime}\left(k_{j}\right)=0$ Markets are competitive; thus labor and capital earn their marginal products, and firms earn zero profits. The price of services is denoted by $p(t)$. The rate of interest, $r^{*}$, is fixed in international market. The wage rate, $w(t)$, is determined in domestic market. Hence, for any individual firm, $r^{*}$ and $w(t)$ are given at any point of time. The production sectors choose the two variables, $k_{j}(t)$ and $N_{j}(t)$ to maximize the profits. The marginal conditions are

$$
r^{*}+\delta_{k}=f_{i}^{\prime}\left(k_{i}\right)=p f_{s}^{\prime}\left(k_{s}\right), w(t)=f_{i}\left(k_{i}\right)-k_{i} f_{i}^{\prime}\left(k_{i}\right)=p\left[f_{s}\left(k_{s}\right)-k_{s} f_{s}^{\prime}\left(k_{s}\right)\right]
$$

As $r^{*}$ is fixed, from $r^{*}+\delta_{k}=f_{i}^{\prime}$ and $w=f_{i}-k_{i} f_{i}^{\prime}$ we obtain that both $k_{i}(t)$ and $w(t)$ are functions of $r^{*}$ as

$$
k_{i}=g_{i}\left(r^{*}\right), \quad w=h\left(r^{*}\right)
$$

It is straightforward to show $d g_{i} / d r^{*}=1 / f^{\prime \prime}<0$ and $d h / d r^{*}=-g_{i}<0$. From $r^{*}+\delta_{k}=p f_{s}^{\prime}$ and $w=p\left(f_{s}-k_{s} f_{s}^{\prime}\right)$, we have $f_{s} / \dot{f}_{s}-k_{s}=h /\left(r^{*}+\delta_{k}\right)$. From this equation, we also solve $k_{s}$ as a function of $r^{*}$, denoted by $k_{s}=g_{s}\left(r^{*}\right)$. Take derivatives of the above equation with regard to $r^{*}$

$$
\frac{f_{s} \hat{f}_{s}^{\prime \prime}}{f_{s}^{\prime 2}} \frac{d k_{s}}{d r^{*}}=\frac{g_{i}}{r^{*}+\delta_{k}}+\frac{h}{\left(r^{*}+\delta_{k}\right)^{2}}>0
$$

As $f_{s} f_{s}^{\prime \prime} / f_{s}^{\prime 2}<0$, we conclude $d k_{s} / d r^{*}<0$. From $r^{*}+\delta_{k}=p f_{\mathrm{s}}^{\prime}$, we obtain

$$
\frac{d p}{d r^{*}}=\frac{1}{f_{s}^{\prime}}-\frac{\left(r^{*}+\delta_{k}\right) f_{s}^{\prime \prime}}{f_{s}^{\prime 2}} \frac{d k_{s}}{d r^{*}}=\frac{1}{f_{s}^{\prime}}-\frac{g_{i}}{f_{s}}-\frac{h}{\left(r^{*}+\delta_{k}\right) f_{s}}
$$


The total capital stocks, $k(t)$ is used by the three domestic sectors. The capital stock is owned either by domestic residents and the rest of the world. As full employment of labor and capital is assumed, we have

$$
K_{i}(t)+K_{s}(t)+K_{h}(t)=K(t), \quad N_{i}(t)+N_{s}(t)=N,
$$

where $K_{h}(t)$ is the capital stocks employed by the housing sector. We rewrite the above equations as

$$
N_{i}(t) k_{i}+N_{s}(t) k_{s}+K_{h}(t)=K(t), \quad N_{i}(t)+N_{s}(t)=N,
$$

where we use $K_{j}=k_{j} N_{j}$. We now describe housing production and behavior of households.

We assume that all housing is residential. The housing industry supplies housing services by combining land and capital. Let us denote $c_{h}(\omega, t)$ housing service received by the household at location $\omega$. We specify the housing service production function as follows

$$
c_{h}(\omega, t)=A_{h} k_{h}^{\alpha_{h}}(\omega, t) L_{h}^{\beta_{h}}(\omega, t), \alpha_{h}+\beta_{h}=1, A_{h}, \alpha_{h}, \beta_{h} \geq 0,
$$

where $k_{h}(\omega, t)$ is the input level of capital per household and $L_{h}(\omega, t)$ is the lot size of the household at location $\omega .^{9}$ It is assumed that the capital-land ratio is always perfectly adjusted. ${ }^{10}$ Let $R(\omega, t)$ and $R_{h}(\omega, t)$ stand for, respectively, the land rent and housing rent at location $\omega$. The marginal conditions for the housing sector are given by

$$
r^{*}+\delta_{k}=\frac{\alpha_{h} R_{h} c_{h}}{k_{h}}, R=\frac{\beta_{h} R_{h} c_{h}}{L_{h}}, 0 \leq \omega \leq L
$$

We have $n(\omega, t)=1 / L_{h}(\omega, t), 0 \leq \omega \leq L$, where $n(\omega, t)$ is the residential density at location $\omega$. The total capital stocks employed by the housing sector is equal to the sum of the capital stocks for housing over space at any point of time. The relationship between $k_{h}(\omega, t)$ and $K_{h}(t)$ is thus given by $K_{h}(t)=\int_{0}^{L} n(\omega, t) k_{h}(\omega, t) d \omega$ Each worker may get income from land ownership,

${ }^{9}$ This equation means that housing demand and supply are equal at any location and at any point of time. ${ }^{10}$ Our approach is mainly based on Anas (1978). Issues related to durability of real estates and its costly conversion and replacements are also discussed by Anas. See also Arnott (1980), Arnott et al. (1999) and Glaeser and Gyourko (2005) for introducing some realistic aspects of housing market to the growth model. The recent literature is referred to Zabel (2004) and Lin et al (2004). 
wealth and wage. To simplify the model, we assume the land is equally owned by the population. This implies that the revenue from land is equally shared among the population. The total land revenue, $\bar{R}(t)$ is given by $\bar{R}(t)=\int_{0}^{L} R(\omega, t) d \omega$. The income from land per household, $\bar{r}(t)$ is given by $\bar{r}(t)=\bar{R}(t) / N$ The consumer at $\omega$ makes decisions on choice of lot size, consumption levels of industrial goods and services as well as on how much to save. This study uses the approach to consumers' behavior proposed by Zhang in the early 1990s. The implications of this approach are similar to those in the Keynesian consumption function and models based on the permanent income hypothesis, which are empirically much more valid than the approaches in the Solow model or in Ramsey model. The approach to household behavior in this study is discussed at length by Zhang (2005, 2008a, 2008b). Let $k(\omega, t)$ stand for the per capita wealth (excluding land) owned by the typical household in location $\omega$. The household at $\omega$ obtains income

$$
y(\omega, t)=r^{*} k(\omega, t)+w+\bar{r}(t), 0 \leq \omega \leq L,
$$

from the interest payment, $r^{*} k$, and the wage payment, $w$ and the land rent income, $\bar{r}$. We call $y(\omega, t)$ the current income in the sense that it comes from consumers' wages and current earnings from ownership of wealth. The disposable income at any point of time is then equal to

$$
\hat{y}(\omega, t)=y(\omega, t)+k(\omega, t)
$$

The disposable income is used for saving and consumption.

At each point of time, a consumer at location $\omega$ distributes the total available budget among the leisure time, $T_{h}(\omega)$, housing, $c_{h}(\omega, t)$, consumption of services, $c_{s}(\omega, t)$, consumption of industrial goods, $c_{i}(\omega, t)$, and saving, $s(\omega, t)$, Here, we assume that the leisure is only dependent on the residential location as the work time is fixed and equal for each household, in disregard of residential location. After the work time is decided, the households decide the time distribution between leisure and traveling to work. As we assume that the travel time from the CBD to the residential location is only related to the distance and neglect any other effects such on technological change, infrastructure improvement, and congestion on the travel time form the CBD to the residential area, the leisure time, which is equal to the fixed total time minus the travel time, is only related to location. Let $T_{0}$ and $\Gamma(\omega)$ respectively stand for the total available time for travel and leisure and 
the time spent on traveling between the residence and CBD. We have $T_{h}(\omega)=T_{0^{-}}$ $\Gamma(\omega)$. The budget constraint is given by

$$
R_{h}(\omega, t) c_{h}(\omega, t)+p c_{s}(\omega, t)+c_{i}(\omega, t)+s(\omega, t)=\hat{y}(\omega, t)
$$

Equation (8) means that the consumption and saving exhaust the consumers' disposable personal income.

Location choice is closely related to the existence and quality of physical environmental attributes such as open space and noise pollution as well as social environmental quality. We assume that utility level, $U(\omega, t)$, of the household at location $\omega$ is dependent on $T_{h}(\omega), c_{h}(\omega, t), c_{S}(\omega, t), c_{l}(\omega, t)$ and $s(\omega, t)$ as follows

$$
\begin{array}{r}
U(\omega, t)=\theta(\omega, t) T_{h}^{\sigma}(\omega) c_{h}^{\eta}(\omega, t) c_{s}^{\gamma}(\omega, t) c_{i}^{\xi}(\omega, t) s^{\lambda}(\omega, t), \\
\eta+\gamma+\xi+\lambda=1, \quad \sigma, \eta, \gamma, \xi, \lambda>0,
\end{array}
$$

in which $\sigma, \eta, \gamma, \xi$, and $\lambda$ are a typical person's elasticity of utility with regard to leisure time, housing, services, industrial goods, and saving at $\omega$. We call $\sigma, \eta, \gamma, \xi$, and $\lambda$ propensities to use leisure time, to consume housing, to consume services, to consume industrial goods, and to hold wealth, respectively. We specify the amenity, $\theta(\omega, t)$, at $\omega$ as follows: $\theta(\omega, t)=\theta_{1} n^{\mu}(\omega, t), \theta_{1}>0$. The function, $\theta(\omega, t)$ implies that the amenity level at location $\omega$ is related to the residential density at the location. For simplicity, we restrict the analysis to the case that all households obtain the same level of utility at any point of time, that is, $U(\omega, t)=U\left(\omega^{2}, t\right)$, $0 \leq \omega_{1}, \omega_{2} \leq L$.

Maximizing $U(\omega, t)$ subject to the budget constraint (7) yields

$$
c_{h}(\omega, t)=\frac{\eta \hat{y}(\omega, t)}{R_{h}(\omega, t)}, c_{s}(\omega, t)=\frac{\hat{\gamma}(\omega, t)}{p}, c_{i}(\omega, t)=\xi \hat{y}(\omega, t), s(\omega, t)=\lambda \hat{y}(\omega, t)
$$

The above equations mean that the housing consumption, consumption of services and saving are positively proportional to the available income.

According to the definition of $s(\omega, t)$, the wealth accumulation for the household at location $\omega$ is given by

$$
\dot{k}(\omega, t)=s(\omega, t)-k(\omega, t), 0 \leq \omega \leq L
$$

The total population is distributed over the whole urban area, that is 
$\int_{0}^{L} n(\omega, t) d \omega=N$. The total consumption of services, $C_{s}(t)$, is given by $C_{s}(t)=\int_{0}^{L} n(\omega, t) c_{s}(\omega, t) d \omega$. The balance of demand and supply in services market is given by $C_{s}(t)=F_{s}(t)$. The national wealth, $\bar{K}(t)$, (excluding the land) is equal to the sum of the wealth owned by all the households, that is $\bar{K}(t)=\int_{0}^{L} k(\omega, t) n(\omega, t) d \omega$. The total consumption, $C_{i}(t)$, and the national saving, $S(t)$, are

$$
C_{i}(t)=\int_{0}^{L} n(\omega, t) c_{i}(\omega, y) d \omega, S(t)=\int_{0}^{L} S(\omega, t) n(\omega, t) d \omega
$$

We introduce $B(t)$ as the value of the economy's net foreign assets at $t$ The income from the net foreign assets, which may be either positive, zero, or negative, is given by $r^{*} B(t)$. The national industrial output is equal to the national net saving, that is

$$
S(t)+C_{i}(t)-\bar{K}(t)-r^{*} B(t)+\delta_{k} K(t)=F_{i}(t)
$$

It should be noted that $\bar{K}(t)$ is the national wealth and $K(t)$ is the total capital stocks employed by the economy. They may not equal as the economy is open.

We now explain trade balance in the model. In the rest of the paper, we omit $\omega$ or/and $t$ in expressions, wherever without causing confusion. According to the definitions of the national wealth, the capital stocks employed by the economy and the net foreign assets, we have $\bar{K}(t)=K(t)+B(t)$. Multiplying the two sides of equation (6) and then integrating the resulted equation from 0 to $L$ with regard to $\omega$, we have $Y(t)=r^{*} \bar{K}+w N+\bar{R}$, where $Y(t)$ is the national current income given by $Y(t)=\int_{0}^{L} y(\omega, t) n(\omega, t) d \omega$. Substituting $\bar{K}=K_{i}+K_{s}+K_{h}+B$ into $Y(t)=r^{*} \bar{K}+w N+\bar{R}$ yields

$$
Y=\left(r^{*} K_{i}+w N_{i}\right)+\left(r^{*} K_{s}+w N_{s}\right)+r^{*} K_{h}+\bar{R}+E
$$

in which we use $N_{i}+N_{s}=N$ and $E(t) \equiv r * B$. From equations (1), we have

$$
r^{*} K_{i}+w N_{i}=F_{i}-\delta_{k} K_{i}, r^{*} K_{s}+w N_{s}=p F_{s}-\delta_{k} K_{s}
$$

By equations (5), we have

$$
\left(r^{*}+\delta_{k}\right) \int_{0}^{L} k_{h}(\omega) n(\omega) d \omega=\alpha_{h} \int_{0}^{L} R_{h}(\omega) c_{h}(\omega) n(\omega) d \omega,
$$




$$
\int_{0}^{L} R(\omega) d \omega=\beta_{h} \int_{0}^{L} R_{h}(\omega) c_{h}(\omega) n(\omega) d \omega
$$

Adding equations (15) and (16) yields

$$
\left(r^{*}+\delta_{k}\right) K_{h}+\bar{R}=F_{h} \equiv \int_{0}^{L} R_{h}(\omega) c_{h}(\omega) n(\omega) d \omega
$$

The variable, $F_{h}(t)$ is the national output of the housing sector. Substituting equations (14) and (17) into equation (13) yields $Y=F-\delta_{k} K+E$, where $F(t) \equiv F_{i}+p F_{s}+F_{h}$, is the national output. The current income of the households is equal to the sum of the economy's net output, $F-\delta_{k} K$, and the country's interest earned on foreign assets, $r^{*} B$. The gross national product (GNP) is measured as the sum of the value of the net output produced within its borders and net international factor payments. The GNP is given by $F+E$. The output produced within the country's geographical borders is called gross domestic product (GDP), The GDP is given by $F$. A country's current balance at time $t$ is the change in the value of its net claims over the rest of the world - the change in its net foreign assets. If $\dot{B}(t)>0$, the economy as a whole is lending (in this case we say that the current account balance is in surplus); if $\dot{B}(t)<0$, the economy as a whole is borrowing (the current account balance is in deficit); and if $\dot{B}(t)=0$, the economy as a whole is neither borrowing nor lending (the current account balance is in balance).

We have thus built the dynamic growth model with endogenous spatial distribution of wealth, consumption and population, capital accumulation and residential location. It can be shown that equation (12) is redundant in the sense that it can be derived from the other equations in the system.

\section{The Dynamics of the Spatial Economy}

The dynamic system consists of many equations. The following theorem shows that the dynamics can be expressed by a single differential equation with the national wealth, $\bar{K}(t)$.

Theorem 1: For a given rate of interest, $r^{*}$, the capital intensities, $k_{i}$ and $k_{s}$ the price of services, $p$, the wage rate, $w$, and the per-worker output levels of the industrial and services sectors, $f_{i}$ and $f_{s}$ are uniquely determined as functions of $r^{*}$. Assume that the initial distribution of personal wealth is invariant in space, that is 
$k\left(\omega_{1}, 0\right)=k\left(\omega_{2}, 0\right)$, for $0 \leq \omega_{1}, \omega_{2} \leq L$. The dynamics of the national wealth, $\bar{K}(t)$, is explicitly solved as follows

$$
\bar{K}(t)=\left\{\bar{K}(0)-\frac{N_{0}}{1-\lambda_{0}}\right\} e^{-\left(1-\lambda_{0}\right) t}+\frac{N_{0}}{1-\lambda_{0}},
$$

in which $\lambda_{\mathrm{o}}$ and $N_{\mathrm{o}}$ are functions of $r^{*}$ defined by

$$
\begin{aligned}
& \lambda_{0} \equiv\left(1+r^{*}\right) \lambda \lambda_{1}, \quad N_{0} \equiv\left\{f_{i}-\left(r^{*}+\delta_{k}\right) k_{i}\right\} \lambda \lambda_{1} N>0, \\
& \lambda_{1} \equiv \frac{1}{\xi+\lambda+\left\{f_{i}-\left(r^{*}+\delta_{k}\right) k_{i}\right\} \gamma / p f_{s}+\left(r^{*}+\delta_{k}\right) k_{s} \gamma / p f_{s}+\alpha_{h} \eta}>0 .
\end{aligned}
$$

At any point of time, all the other variables are determined as unique functions of $\bar{K}(t)$ by the following procedure: $\hat{Y}(t)$ by (A6) $\rightarrow K(t)$ by $(\mathrm{A} 5) \rightarrow N_{s}(t)$ and $N_{i}(t)$ by $(\mathrm{A} 4) \rightarrow K_{j}(t)=k_{j} N_{j}(t), j=i, s \rightarrow \hat{y}(t)=\hat{Y}(t) / N \rightarrow k_{h}(t)$ by (A12) $\rightarrow$ $F_{j}(t)=N_{j} f_{j}(t), j=i, s \rightarrow C_{i}(t), C_{s}(t), K_{h}(t)$ and $S(t)$ by (A2) $\rightarrow n(\omega)$ by (A14) and $(\mathrm{A} 15) \rightarrow k_{h}(t)$ by $(\mathrm{A} 14) \rightarrow R_{h}(\omega)$ by $(\mathrm{A} 13) \rightarrow L_{h}(\omega)=1 / n(\omega) \rightarrow$ $c_{h}(\omega, t)=k_{h}^{\alpha_{h}}(t) L_{h}^{\beta_{h}}(\omega) \rightarrow R(\omega)$ by $(5) \rightarrow \bar{r}(t)$ by $(\mathrm{A} 7) \rightarrow c_{s}(t), c_{i}(t)$ and $s(t)$ by (9) $\rightarrow B(t)=\bar{K}(t)-K(t) \rightarrow E(t)=r B(t)$.

From Theorem 1, we conclude that if per capita wealth at the initial time is independent of location, then we can explicitly solve all the variables as functions of the preference and technologies over time and space. As we explicitly solved the model, it is straightforward to determine equilibrium and stability properties of the spatial model. This theorem is important as it gives a complete description of the spatial economy. It also explicitly shows how the economic mechanisms in the Solow and Uzawa neoclassical growth models and the Alonso and Muth urban models are interrelated. These interrelations between economic growth and spatial economy cannot be observed in the Solow and Uzawa neoclassical growth models and the Alonso and Muth urban models.

As proved in the Appendix, if the initial distribution of the wealth is homogenous over space, then the per-capita wealth, $k(\omega)$, and disposable income, $\hat{y}(\omega)$, are homogenous over space. That is $k\left(\omega_{1}, t\right)=k\left(\omega_{2}, t\right), \hat{y}\left(\omega_{1}, t\right)=\hat{y}\left(\omega_{2}, t\right)$. This implies that all residents receive the same income and own the same amount of wealth at each point of time. The residential distribution is given by equations (A14) and (A15). That is 


$$
\frac{n\left(\omega_{1}\right)}{n\left(\omega_{2}\right)}=\left(\frac{T_{h}\left(\omega_{1}\right)}{T_{h}\left(\omega_{2}\right)}\right)^{\beta_{0}}, n(0)=\frac{N T_{h}^{\beta_{0}}(0)}{\int_{0}^{L} T_{h}^{\beta_{0}}(\omega) d \omega}, 0 \leq \omega_{1}, \omega_{2} \leq L
$$

where $\beta_{0}=\sigma /\left(\eta \beta_{n}-\mu\right)$. The residential density is invariant over time. The conclusion comes from the assumptions that the population is fixed, the land is equally shared among the residents, there is no congestion, no transportation costs, no investment in the transportation infrastructure, and no technological change in transportation systems. If any of these assumptions is relaxed, then $n(\omega)$ may become time-dependent.

We now examine changes of the residential density over space. As $T_{h}\left(\omega_{1}\right) /$ $T_{h}\left(\omega_{2}\right)>1$ if $\omega_{1}<\omega_{2}$, we see that if $\beta_{0}>0$, then $n\left(\omega_{1}\right)>n\left(\omega_{2}\right)$. The residential density is higher nearer the CBD. As traveling costs more as the residence is further away from the $\mathrm{CBD}$, it is reasonable to observe the declination of the residential density as the distance from the CBD increases. Yet, if $\beta_{0}<0$ the residential density distribution is inverse to the case of $\beta_{0}>0$ in the sense that the further the residential location is away from the CBD, the higher the density is. To see why this happens, from the definition of $\beta_{0}$ we see that the parameter becomes negative only when $\mu>\eta \beta_{n}>0$. A positive $\mu$ means that as the residential density rises, the local attractiveness is increased. The condition, $\mu>\eta \beta_{n}$, implies that the individual welfare is positively strongly affected by, for instance, social interactions among local people and the propensity to use land is low. ${ }^{11}$ As people highly evaluate interacting with each other among locals, the urban residential density becomes higher further away from the CBD. In this study, we limit our examination to the case of $\mu<\eta \beta_{n}$.

By equation (9) and the condition of equalization of the utility levels, we have $R_{h}\left(\omega_{1}\right) / R_{h}\left(\omega_{2}\right)=\left(n\left(\omega_{1}\right) / n\left(\omega_{2}\right)\right)^{\beta_{h}}$. This equation implies that the ratio of housing rents between any two locations is invariant time. As $n\left(\omega_{1}\right)>n\left(\omega_{2}\right)$, we see that the housing rent declines as the residential area is further away from the CBD. By equations (8), we have

$$
c\left(\omega_{1}\right)=c\left(\omega_{2}\right), \frac{c_{h}\left(\omega_{1}\right)}{c_{h}\left(\omega_{2}\right)}=\frac{R_{h}\left(\omega_{2}\right)}{R_{h}\left(\omega_{1}\right)}, s\left(\omega_{1}\right)=s\left(\omega_{2}\right) .
$$

${ }^{11}$ Substituting equation (2) into (7), we have $U=\theta T_{h}^{\sigma} c^{\xi} k_{h}^{\eta \alpha_{h}} L_{h}^{\eta \beta_{h}} s^{\lambda}$. Hence, we may interpret as the propensity $\eta \beta_{h}$ to use land. 
The consumption of services is invariant in location but changeable in time. This property comes from that the households have the same income, the same propensity to consume goods, and the price of the goods are invariant in space. Consumption of housing increases as the residential area is further from the CBD. It should be noted that the total expenditure on housing by per household, $R_{h}(\omega, t) c_{h}(\omega, t)$, is invariant in space but changeable in time. That is $R_{h}\left(\omega_{1}, t\right) c_{h}\left(\omega_{1}, t\right)=R_{h}\left(\omega_{2}, t\right) c_{h}\left(\omega_{2}, t\right)$.

\section{Spatial Economic Equilibrium}

For simulation we also need to specify forms of the production functions. In the rest of the paper, we specify the production functions in the Cobb-Douglas forms

$$
F_{j}(t)=A_{j} K_{j}^{\alpha_{j}} N_{j}^{\beta_{j}}, \alpha_{j}+\beta_{j}=1, \alpha_{j}, \beta_{j}>0, j=i, s
$$

Following Theorem 1, we can determine all the variables as functions of $\bar{K}(t)$. By equations (1) and (18), we have $k_{s}=a k_{i}, f_{j}=A_{j} k_{j}^{\alpha_{j}}$, where $\alpha=\beta_{i} \alpha_{s} / \alpha_{i} \beta_{s}$. By equations (1) and $p=f_{i}^{\prime} / f_{s}^{\prime}$, we solve

$$
k_{i}=\left(\frac{\alpha_{i} A_{i}}{r^{*}+\delta_{k}}\right)^{1 / \beta}, w=\beta_{i} A_{i} k_{i}^{\alpha}, p=\alpha_{p} k_{i}^{\beta_{s}-\beta_{i}}
$$

where $\alpha_{p} \equiv \alpha_{i} A_{i} \alpha^{\beta_{s}} / \alpha_{s} A_{s}$. We consider $w, p$, $k_{j}$, and $f_{j}, j=i$, $s$, as parameters.

We now calculate the equilibrium values of all the variables and examine effects of some parameters on the economic geography by simulation. We specify values of the parameters

$$
\begin{aligned}
& r^{*}=0.03, A_{i}=1.4, A_{s}=1.2, A_{h}=1.1, N=10, L=5, \\
& \alpha_{i}=0.3, \alpha_{s}=0.4, \alpha_{\mathrm{h}}=05, \\
& \eta=0.05, \gamma=0.05, \xi=0.03, \\
& \sigma=0.2, \mu=-0.2, T_{0}=1, v=0.03, \delta_{k}=0.05
\end{aligned}
$$

The rate of interest is internationally fixed at 3 per cent. The population is fixed at 10 units and the urban size at 5 units. The total productivity of the housing sector is equal to 1.1; the total productivities of the industrial and services sectors are respectively equal to 1.4 and 1.2, We specify the parameters, $\alpha_{i}, \alpha_{s}$ and $\alpha_{h}$ respectively with $0.3,0.4$ and 0.5 . Some empirical studies on the US economy 
demonstrate that the value of the parameter, $\alpha$, in the Cobb-Douglas production is approximately equal to 0.3 (for instance, Abel and Bernanke, 1998). The propensities to consume housing, services and industrial goods are respectively specified at $0.05,0.05$ and 0.03 . The ratio between the expenditures on housing and other goods and services is about 0.625 . The propensity to use leisure is specified at 0.2 . The amenity parameter, $\mu$ is negative. This implies that the households prefer to living in an area with low residential distribution. The total available time is fixed at unit and $v=0.03$ means that if the total travel time from the CBD to the other end of the system will use up 15 per cent of the total available time. The depreciation rate is specified at 0.05 . Although the choice of some parameters, such as the population and urban size, is arbitrary, we can still obtain robust insights as we will vary (some of) these parameters in the following comparative static analysis.

Following Theorem 1 and applying (20), we calculate the equilibrium values of the location-independent variables and the residential density closest to the CBD as follows

$$
\begin{aligned}
& w=1.995, p=0.900, k_{i}=10.686, k_{s}=16.622, f_{i}=2.850, \\
& f_{s}=3.694, N_{i}=6.198, \\
& N_{s}=3.802, K_{i}=66.226, K_{s}=63.202, \\
& F_{i}=17.660, F_{s}=14.044, k=20.843, \\
& r=0.632, \hat{y}=24.095, \\
& c_{s}=1.339, c_{i}=0.723, s=20.963, n(0)=2.144 .
\end{aligned}
$$

The wage rate and the price of services are respectively 2 and 0.9. The capital intensity of the services sector is higher than of the industrial sector. The product per labor force of the services sector is also higher than that of the industrial sector.

Figure 2. The Equilibrium Values of the Location-Dependent Variables
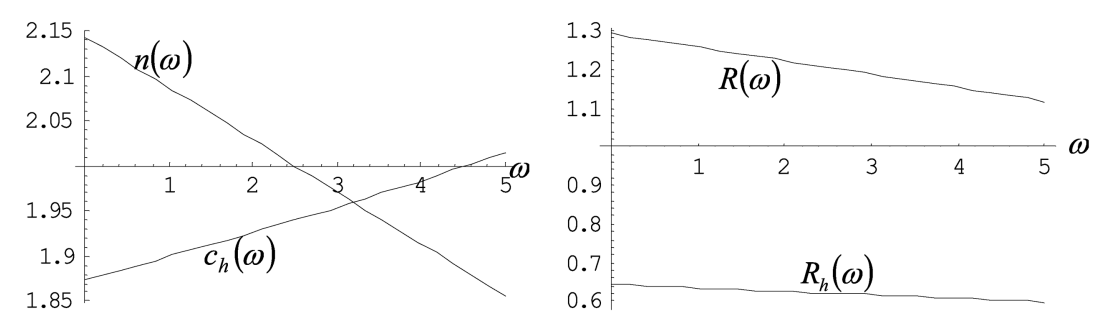
About 38 per cent of the total labor force is employed by the service sector and 62 per cent by the industrial sector. We now plot the equilibrium values of the location-dependent variables as in Figure 2. The residential density declines and the housing consumption increases in the distance from the CBD to the residential site. Both the housing rent and land rent fall in distance. The housing rent curve is slower than that of the land rent. As the housing services is produced by combining land and capital and the rate of interest is invariant with space, it is expected that the housing rent curve is slower than that of the land rent.

We now examine the shares of the three sectors in the national product, $F(t)$. The national product, $F$, the national wealth, $\bar{K}$, the total capital stocks employed by the economy, $K$, and the foreign assets, $B$ are

$$
F=42.941, \bar{K}=219.94, K=208.43, B=\bar{K}-K=11.512 .
$$

The shares of the three sectors are

$$
\tilde{F}_{i} \equiv \frac{F_{i}}{F} 100=41.13, \tilde{F}_{s} \equiv \frac{p F_{s}}{F} 100=29.44, \tilde{F}_{h} \equiv \frac{F_{h}}{F} 100=29.44
$$

The shares of the output values of the industrial goods, services, and housing sectors are respectively 41.1 per cent, 29.4 per cent, and 29.4 per cent.

We now examine effects of changes in some parameters on the locationdependent variables. ${ }^{12}$ First, we examine effects of changes in the amenity parameter, $\mu$. We allow it to change from -0.9 to -0.1 . From Figure 3 , we see that as the parameter changes from -0.9 to -0.1 , the residential density, the housing consumption, the housing rent and land rent all become increasingly steeper. We see that the residential amenity has a strong effect on the urban configuration. As a rise in $\mu$ implies that the residential density tends to have less effect on the amenity level, a rise in the value of the parameter tends to reduce spatial effects of the residential concentration. Hence, as $\mu$ is increased, the space-dependent variables tend to become steeper.

\section{The Motion of the Dynamic System}

The previous section studies the equilibrium structure of the economic geography. As we have already explicitly solved the motion of all the variables

\footnotetext{
${ }^{12}$ As these parameters will not affect the national economic production and income, we don ${ }^{\circ} Ø \mathrm{t}$ mention the location-independent variables in the rest of this section.
} 
Figure 3. The Economic Geography and the Amenity Parameter

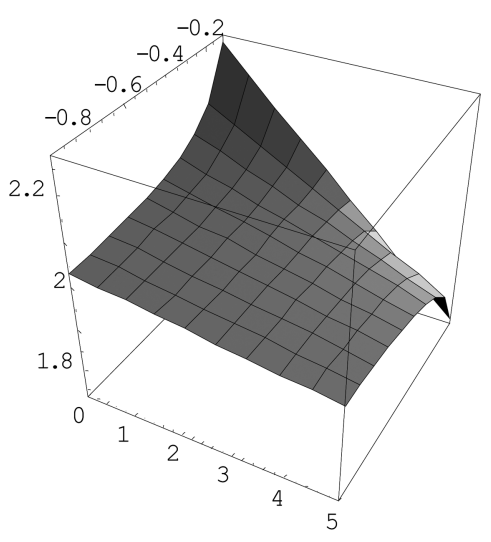

a) the residential density distribution

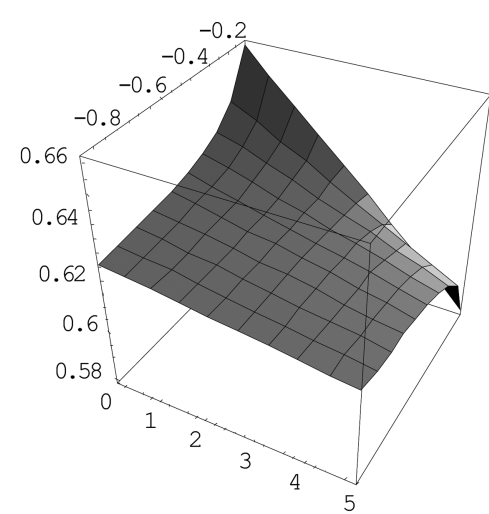

c) the housing rent

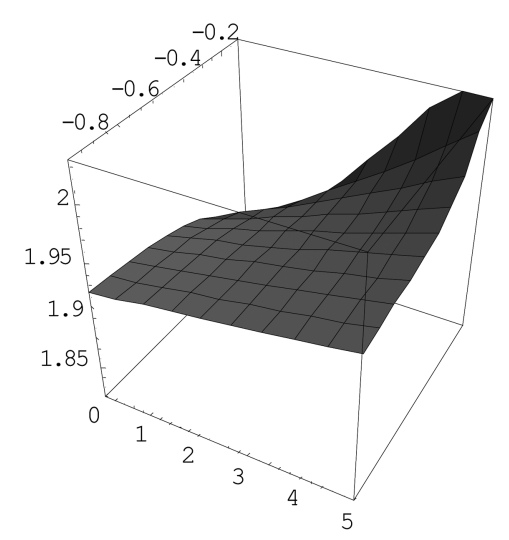

b) the per capita housing consumption

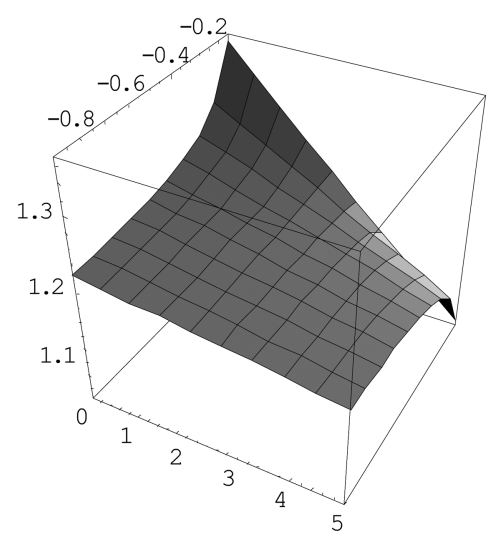

d) the land rent

over time and space, it is straightforward to plot the motion. First, let us examine the motion of the system when the initial condition is away from the stationary state with $\bar{K}(0)=180$ under (20). We have already shown that the dynamic system has a unique stable equilibrium point. The equilibrium values are provided in (21) and Figure 2. The initial state of the national wealth is lower than its corresponding long-run equilibrium value for the given technology and preference. Figure 4 shows the change of the variables over time and space.

Figure 4a shows that as time passes the capital stocks of the industrial and service sector rise and the capital stocks of the housing sector falls. The initial values of $K_{i}$ and $K_{s}$ are lower than their equilibrium values and the initial value of $K_{h}$ is higher than its equilibrium value. From Figure $4 \mathrm{~b}$, we see that some of the 
Figure 4. The Motion of the System
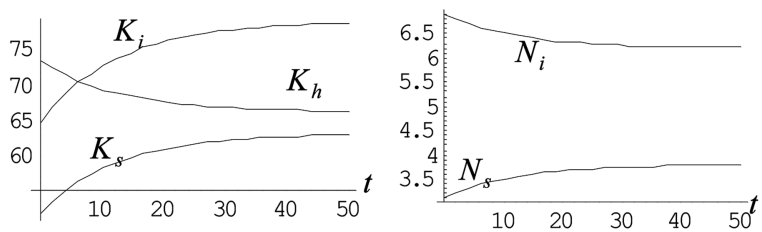

(a) $K_{i}(t), K_{s}(t)$ and $K_{h}(t)$ (b) $N_{i}(t)$ and $N_{s}(t)$

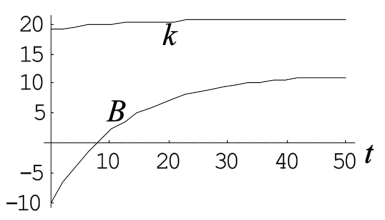

(c) $B(t)$ and $k(t)$

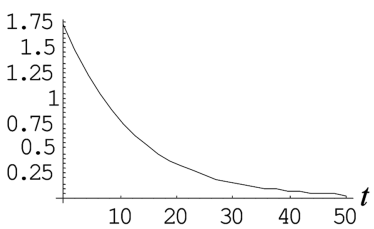

(d) $\dot{B}(t)$

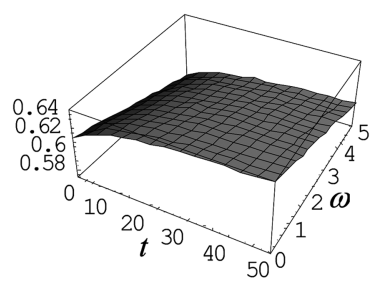

(g) $R_{h}(\omega, t)$

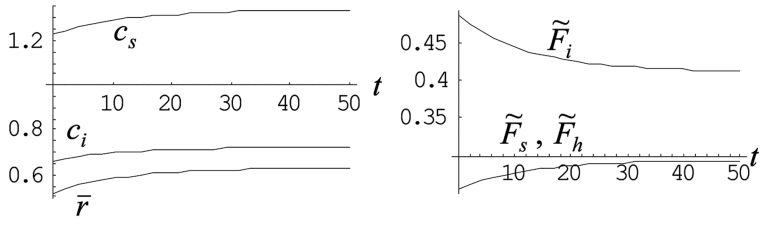

(e) $\bar{r}(t), c_{i}(t)$ and $c_{s}(t)$

(f) $\widetilde{F}_{i}(t), \widetilde{F}_{s}(t)$ and $\widetilde{F}_{h}(t)$

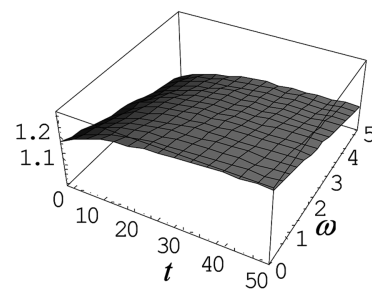

(h) $R(\omega, t)$

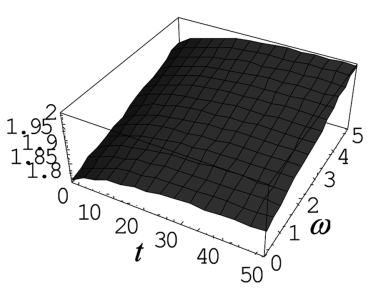

(i) $c_{h}(\omega, t)$

labor force employed by the industrial sector is employed by the service sector as time passes. The net value of foreign asset, $B(t)$, is negative in the initial periods. As the economy is further developed, the value becomes positive. During the simulation period, the current account balance is in surplus. The per-capita consumption levels of services and the industrial goods rise and the rent income

Figure 5. The National Output and the Growth Rate

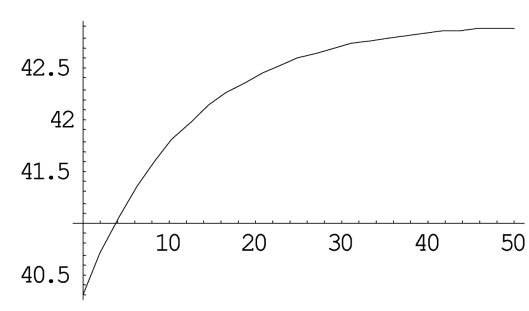

(a) $F(t)$

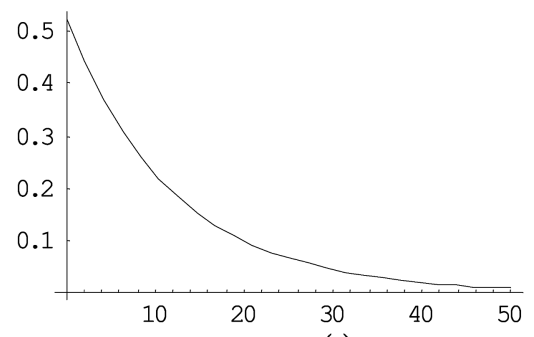

(b) $g(t)$ 
from land also rises. During the simulation period, the share of the industrial goods falls and the shares of the services and housing sectors increase. The housing rent, land rent and consumption of housing all rise at any residential location. We plot the national output and the growth rate of the national output as in Figure 5. The growth rate gradually declines until it achieves the long-term stationary state.

\section{Comparative Dynamic Analysis by Simulation}

This section examines what will happen to the dynamic system if some parameters are shifted. First, we study possible effects of changes in the rate of interest. We increase $r^{*}$ from 0.03 to 0.04 . The effects on the capital intensities of the services and industrial sectors, the wage rate, the price of services, and the perworker output levels are given by

Figure 6. A Rise in the Rate of Interest

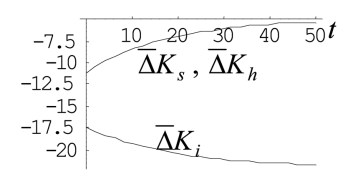

(a) $\bar{\Delta} K_{i}(t), \bar{\Delta} K_{s}(t)$ and $\bar{\Delta} K_{h}(t)$

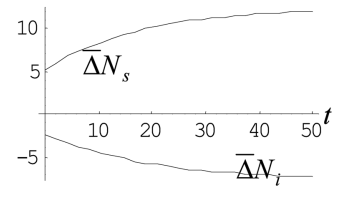

(b) $\bar{\Delta} N_{i}(t)$ and $\bar{\Delta} N_{s}(t)$

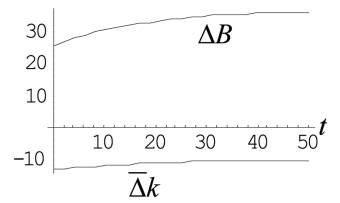

(c) $\Delta B(t)$ and $\bar{\Delta} k(t)$
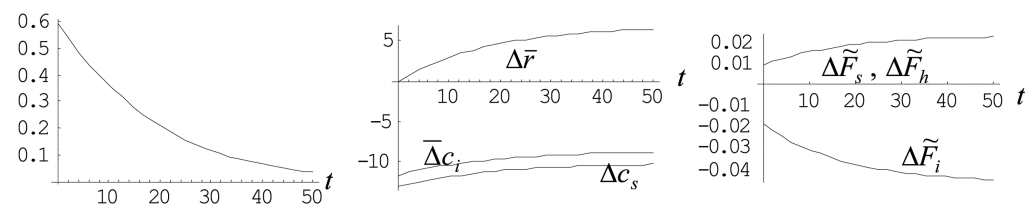

(d) $\Delta \dot{B}(t)$

(e) $\bar{\Delta} \bar{r}(t), \bar{\Delta} c_{i}(t)$ and $\bar{\Delta} c_{s}(t)$

(f) $\Delta \widetilde{F}_{i}(t), \Delta \widetilde{F}_{s}(t)$ and $\Delta \widetilde{F}_{h}(t)$

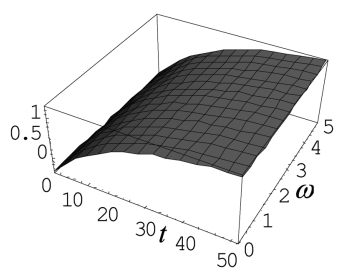

(g) $\bar{\Delta} R_{h}(\omega, t)$

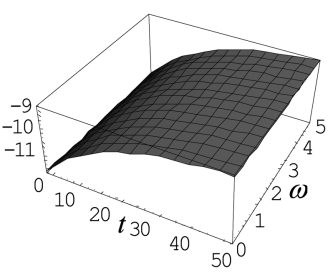

(h) $\bar{\Delta} R(\omega, t)$

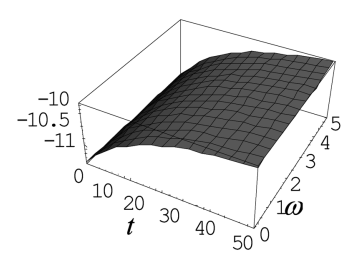

(i) $\bar{\Delta} c_{h}(\omega, t)$ 
Figure 7. The National Output and Growth Rate with a Rise in Rate of Interest

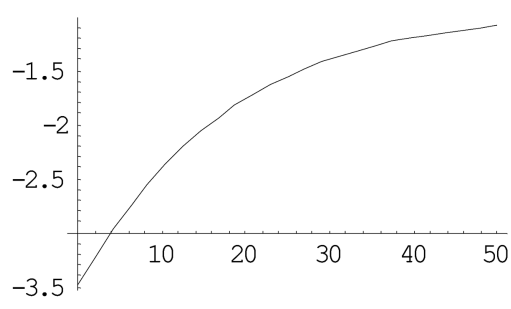

(a) $\bar{\Delta} F(t)$

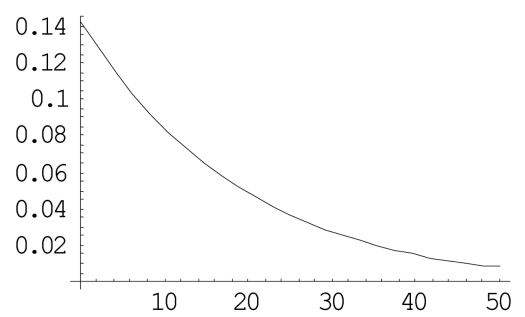

(b) $\Delta g(t)$

$$
\begin{aligned}
& \bar{\Delta} p=1.69, \bar{\Delta} w=-4.92, \bar{\Delta} k_{i}=-15.49 \\
& \bar{\Delta} k_{s}=-15.49, \bar{\Delta} f_{i}=-4.92, \bar{\Delta} k_{i}=, \bar{\Delta} f_{s}=-6.51 .
\end{aligned}
$$

As the capital becomes more expensive in the international market, the capital intensities in the three sectors are reduced. The wage rate becomes lower and the price of services becomes higher. In this study, a variable, $\bar{\Delta} x(t)$, stands for the change rate of the variable, $x(t)$, in percentage due to changes in the parameter value.

We plot the effects of change in the rate of interest in Figure 6. The capital intensities of the services and industrial sectors are reduced. The effects on the other variables are provided in Figure 6. As the rate of interest is increased, the capital stocks employed by the industrial sector falls (in comparison to the corresponding value of the variable if the change in the rate of interest did not occur) and the capital stocks of the services and housing sectors all fall. More labor is employed by the services sector. The national wealth falls and the net value of foreign assets rise. During the simulation period, the current account balance is in surplus. The income from the land is almost no affected, the consumption levels of industrial goods and services fall. The share of the output of the industrial sector in the national out falls and the shares of the other two sectors rise. The rent and consumption of housing are increased, the land rent is reduced.

We plot the effects of changes in the rate of interest on the national output and the growth rate of the national output in Figure 7. The national output is reduced by the rise of interest rate and the growth rate slightly rises. 


\section{Concluding Remarks}

This study proposed a spatial growth model of a small open economy by synthesizing the main ideas in the four important models in the neoclassical growth theory and urban economics. The economic growth with economic geography has a unique long-run stable equilibrium. We also analyzed changes in the parameters upon the system. We have limited our study to a simplified spatial structure of the economic system. The Solow model is the key model in the neoclassical economic growth theory and Alonso model is the key model in the modern urban economics. There are numerous meaningful extensions of either of the two models in the literature. ${ }^{13}$ We may extend our model in many ways on the basis of the literature in the two fields. We may develop the model in a discrete version.

\section{Appendix: Proof Theorem 1}

First, from equations (6) and (7) we get $y(\omega)=\left(1+r^{*}\right) k(\omega)+w+\bar{r}$. Multiplying the above equation by $n(\omega, t)$ and integrating the resulted equation from 0 to $\mathrm{L}$, we have

$$
\hat{Y}(t)=\left(1+r^{*}\right) \bar{K}(t)+w N+\bar{R}(t)
$$

where the total disposal income is defined as $\hat{Y}(t)=\int_{0}^{L} \hat{y}(\omega, t) n(\omega, t) d \omega$. Multiplying all the equations in (8) by $n(\omega, t)$ and then integrating the resulted equations from 0 to $L$ with respect to $\omega$, we obtain

$$
\left(r^{*}+\delta_{k}\right) K_{h}=\alpha_{h} \eta \hat{Y}, C_{s}=\frac{\gamma \hat{Y}}{p}, \quad C_{i}=\xi \hat{Y}, \quad S=\lambda \hat{Y}
$$

where we use $R_{h} c_{h}=\left(r^{*}+\delta_{k}\right) k_{h} / \alpha_{h}$ from equations (5). First we show that the total disposable income, $Y(t)$, can be expressed as a unique function of $\bar{K}(t)$. Substituting $C_{i}=\xi \hat{Y}$ and $S=\lambda \hat{Y}$ in equations (A2) into equation (12) yields

$$
(\xi+\lambda) \hat{Y}-\left(1+r^{*}\right) \bar{K}+\left(r^{*}+\delta_{k}\right) K=f_{i} N_{i}
$$

where we use $F_{i}=f_{i} N_{i}$ and $B=\bar{K}-K$. From $C_{s}=\gamma \hat{Y} / p$ and $C_{s}(t)=F_{s}(t)$, we have

\footnotetext{
${ }^{13}$ For the contemporary literature on urban economics, see Fujita and Thisse (2002) and Henderson and Thisse (2004).
} 
$p F_{s}=\gamma \hat{Y}$. From this equation, $F_{s}=f_{s} N_{s}$, and $N_{i}+N_{s}=N$, we have

$$
N_{s}(t)=\frac{\gamma \hat{Y}(t)}{p f_{s}}, N_{i}(t)=N-\frac{\gamma \hat{Y}(t)}{p f_{s}}
$$

As $p$ and $f_{s}$ are functions of $r^{*}$, the labor distribution is determined by $\hat{Y}(t)$. Substitute equations (A4) and $\left(r+\delta_{k}\right) K_{h}=\alpha_{h} \eta \hat{Y}$ into equation (3)

$$
K(t)=k_{i} N+\left\{\left(k_{s}-k_{i}\right) \frac{\gamma}{p f_{s}}+\frac{\alpha_{h} \eta}{r+\delta_{k}}\right\} \hat{Y}(t)
$$

The total capital stocks employed by the economy, $K(t)$, is a linear function of $\hat{Y}(t)$. Substitute equations (A4) and (A5) into equation (A3)

$$
\bar{K}(t)=\frac{\lambda}{\lambda_{0}} \hat{Y}(t)-\frac{N_{0}}{\lambda_{0}}
$$

The national wealth, $\bar{K}(t)$ is a linear function of $\hat{Y}(t)$. By equations (5), we have $R(t)=\beta h\left(r^{*}+\delta_{k}\right) k_{h} n(\omega) / \alpha_{h}$. Integrating the above equation from 0 to $L$ yields $\bar{r}=\left(r^{*}+\delta k\right) \beta_{h} K_{h} / \alpha_{h} N$. From this equation, $\left(r^{*}+\delta_{k}\right) K_{h}=\alpha_{h} \eta \hat{Y}$ and (A6), we solve

$$
\bar{r}(t)=\left(\bar{K}(t)+\frac{N_{0}}{\lambda_{0}}\right) \frac{\lambda_{0} \beta_{h} \eta}{\lambda N}
$$

in which $\lambda_{0}$ and $N_{0}$ are defined in Theorem 1. By equations (6) and (7), we have

$$
\hat{y}(\omega)=\left(1+r^{*}\right) k(\omega)+w+\bar{r}
$$

Inserting this equation in equation (10), we have

$$
\dot{k}(\omega, t)=\lambda^{*} k(\omega, t)+\lambda[w+\bar{r}(\bar{K}(t))], 0 \leq \omega \leq L
$$

where $\lambda^{*} \equiv \lambda-1+\lambda r^{*}$ and we use $s=\lambda \hat{y}$. This is a linear differential equation in $k(\omega, t)$. The general solution of equation (A9) is given by

$$
\left.k(\omega, t)=e^{r^{*} t}\left(h_{0}+\lambda \int(w+\bar{r}(\bar{K}(\tau)))\right) e^{-r^{*} \tau} d \tau\right)
$$

where $h_{0}$ is a constant to be determined by initial conditions. From equation (A10), we see that if the initial distribution of the wealth is not dependent on location, $h_{0}$ is also independent of location. We conclude that $k(\omega, t)$ is independent of location, 
that is $k\left(\omega_{1}, t\right)=k\left(\omega_{2}, t\right)$. We thus have $k(t)=\bar{K}(t) / N$. By this property and equation (A8), we have $\hat{y}\left(\omega_{1}\right)=\hat{y}\left(\omega_{2}\right)$.

Substituting equations (9) into $U(\omega, t)$ and then using $U(0)=U(\omega)$, we have

$$
\frac{R_{h}(\omega)}{R_{h}(0)}=\left(\frac{n(\omega)}{n(0)}\right)^{\mu / \eta}\left(\frac{T_{h}(\omega)}{T_{h}(0)}\right)^{\sigma / \eta}
$$

where we use $\hat{y}(0)=\hat{y}(\omega)$. From $R_{h}(\omega) c_{h}(\omega)=\eta \hat{y}(\omega)$ and $\left(r^{*}+\delta_{k}\right) k_{h}=\alpha_{h} R_{h} c_{h}$, we have

$$
k_{h}(\omega)=\frac{\alpha_{h} \eta \hat{y}}{r^{*}+\delta_{k}}
$$

Substituting $c_{h}=A_{h} k_{h}^{\alpha_{h}} L_{h}^{\beta_{h}}$ into $\left(r^{*}+\delta k\right) k_{h}=\alpha_{h} c_{h} R_{h}$, we have

$$
R_{h}(\omega)=\frac{\eta^{\beta_{h}}}{A_{h}}\left(\frac{r^{*}+\delta_{k}}{\alpha_{h}}\right)^{\alpha_{h}} n^{\beta_{h}}(\omega) \hat{y}^{\beta_{h}}
$$

where use equation (A12). Substituting equation (A13) into equation (A11) yields

$$
n(\omega)=n(0)\left(\frac{T_{h}(\omega)}{T_{h}(0)}\right)^{\beta_{o}}
$$

where $\beta_{0} \equiv \sigma /\left(\eta \beta_{n}-\mu\right)$. Integrating equation (A14) from 0 to $L$, we obtain

$$
n(0)=\frac{N T_{h}^{\beta_{0}}(0)}{\int_{0}^{L} T_{h}^{\beta_{0}}(\omega) d \omega}
$$

As $T_{h}(\omega)$ is explicitly defined as a function of location and independent of time, we see that $n(0, t)$ is independent of time. By equation (A15), we conclude that $n(\omega)$ is actually independent of time but dependent on location. This property is important for us to find a differential equation for $\bar{K}(t)$. Substituting $s=\lambda \hat{y}$ from equations (9) into equation (10) yields: $\dot{k}=\lambda \hat{y}-k$. Multiplying (A15) by $n(\omega, t)$ and then integrating $\dot{k}=\lambda \hat{y}-k$ from 0 to $L$ with respect to $\omega$ yields $\dot{\bar{K}}=\lambda \hat{Y}-\bar{K}$, where we use

$$
\dot{\bar{K}}(t)=\int_{0}^{L} \frac{d(k(t) n(\omega))}{d t} d \omega=\int_{0}^{L} \dot{k}(t) n(\omega) d \omega,
$$

in which we use $\dot{n}=0$. Inserting equation (A6) in $\dot{\bar{K}}=\lambda \hat{Y}-\bar{K}$, yields 
$\dot{\bar{K}}+\left(1-\lambda_{0}\right) \bar{K}=N_{o}$. The general solution is given in Theorem 1 .

\section{Acknowledgements}

The author is grateful to constructive comments of Prof. Jong Eun Lee and two anonymous referees.

Received 1 February 2008, Revised 4 September 2008, Accepted 4 September 2008

\section{References}

Abdel-Rahman, H.M. (2004), "The City System Paradigm: New Frontiers", in Urban Dynamics and Growth: Advances in Urban Economics (Eds.), Capello, R., Nijkamp, P., Amsterdam: Elsevier.

Abel, A.B. and Bernanke, B.S. (1998), Macroeconomics, $3^{\text {rd }}$ edition. New York: AddisonWesley.

Alonso, W. (1964), Location and Land Use, MA., Cambridge: Harvard University Press. Anas, A. (1978), "Dynamics of Urban Residential Growth", Journal of Urban Economics, 5, pp. 66-87.

Arnott, R.J. (1980), “A Simple Urban Growth Model with Durable Housing”, Regional Science and Urban Economics, 10, pp. 53-76.

Arnott, R. J. (1987), "Economic Theory and Housing", in Handbook of Regional and Urban Economics (Ed.), Mills, E.S., Amsterdam: North-Holland.

Arnott, R., Braid, R., Davidson, R., Pines, D. (1999), "A General Equilibrium Spatial Model of Housing Quality and Quantity", Regional Science and Urban Economics, 29, pp. 283-16.

Baldwin, R.E., Martin, P. (2004), “Agglomeration and Regional Growth”, in Handbook of Regional and Urban Economics (Eds.), J.V. Hendersson, Thisse, J.F., Amsterdam: Elsevier.

Beckmann, M.J. (1969), "On the Distribution of Urban Rent and Residential Density", Journal of Economic Theory, 1, pp. 60-7.

Benhabib, J., Meng, Q.L., Nishimura, K. (2000), "Indeterminacy under Constant Returns to Scale in Multisector Economy", Econometric , 68, pp. 1541-48.

Benigno, G., Benigno, P. (2003), "Price Stability in Open Economies", Review of Economic Studies, 70, pp. 743-64.

Braid, R.M. (2001), "Spatial Growth and Redevelopment with Perfect Foresight and Durable Housing", Journal of Urban Economics, 49, pp. 425-52.

Brito, P.M.B., Pereira, A.M. (2002), "Housing and Endogenous Long-Term Growth", Journal of Urban Economics, 51, pp. 246-71.

Brock, P.L. (1988), "Investment, the Current Account, and the Relative Price of Non- 
traded Goods in a Small Open Economy", Journal of International Economics, 24, pp. 235-53.

Brueckner, J.K. (1981), “A Dynamic Model of Housing Production”, Journal of Urban Economics, 10, pp. 1-14.

Brueckner, J.K., Pereira, A.M. (1994), "Housing Ownership and the Business Cycle", Journal of Housing Economics, 3, pp. 165-85.

Capello, R., Nijkamp, P. (2004, Eds.), Urban Dynamics and Growth: Advances in Urban Economics, Amsterdam: Elsevier.

Diamond, P.A. (1965), "Disembodied Technical Change in a Two-Sector Model”, Review of Economic Studies, 32, pp. 161-68.

DiPasquale, D., Wheaton, W.C. (1996), Urban Economics and Real Estate Markets, Englewood Cliffs: Prentice Hall.

Drugeon, J.P., Venditti, A. (2001), "Intersectoral External Effects, Multiplicities \& Indeterminacies", Journal of Economic Dynamics \& Control, 25, pp. 765-87.

Fujita, M., Thisse, J.F. (2002), Economics of Agglomeration: Cities, Industrial Location, and Regional Growth, Cambridge: Cambridge University Press.

Gali, J., Monacelli, T. (2005), "Monetary Policy and Exchange Rate Volatility in a Small Open Economy", Review of Economic Studies, 72, pp. 707-34.

Glaeser, E.L. (1999), "Learning in Cities", Journal of Urban Economics, 46, pp. 254-77.

Glaeser, E.L., Gyourko, J. (2005), "Urban Decline and Durable Housing", Journal of Political Economy, 113, pp. 345-75.

Henderson, J.V. (1974), “The Sizes and Types of Cities”, American Economic Review, 64, pp. 640-56.

Henderson, J.V. (1985), Economic Theories and Cities, New York: Academic Press.

Henderson, J.V., Kuncoro, A., Turner, M. (1995), "Industrial Development in Cities", Journal of Political Economy, 103, pp. 1067-90.

Henderson, J.V., Thisse, J.F. (2004, Eds.), "Handbook of Regional and Urban Economics, Amsterdam: Elsevier.

Hockman, O., Pines, D. (1980), "Costs of Adjustment and the Spatial Pattern of a Growing Open City", Econometrica, 50, pp. 1371-89.

Kollmann, R. (2001), "The Exchange Rate in a Dynamic-Optimizing Business Cycle Model with Nominal Rigidities: a Quantative Investigation", Journal of International Economics, 55, pp. 243-62.

Kollmann, R. (2002), "Monetary Policy Rules in the Open Economy: Effects on Welfare and Business Cycles", Journal of Monetary Economics, 49, pp. 899-1015.

Lane, P.R. (2001), "The New Open Economy Macroeconomics: a Survey", Journal of International Economics, 54, pp. 235-66.

Leung, C. (2004), "Macroeconomics and Housing: a Review of the Literature", Journal of Housing Economics, 13, pp. 249-67.

Lin, C.C., Mai, C.C., Wang, P. (2004), "Urban Land Policy and Hosing in an Endogenously Growing Monocentric City, Regional Science and Urban Economics, 34, pp. 241-61. 
Lucas, R.E. (1988), "On the Mechanics of Economic Development", Journal of Monetary Economics, 22, pp. 3-42.

Mills, E.S. (1967), “An Aggregative Model of Resource Allocation in Metropolitan Areas", American Economic Review, 57, pp. 197-210.

Muth, R.F. (1969), Cities and Housing, Chicago: University of Chicago Press.

Muth, R.F. (1973), "A Vintage Model of the Housing Stock", Papers of the Regional Science Association, 30, pp. 141-56.

Obstfeld, M., Rogoff, K. (1996), Foundations of International Macroeconomics, Mass., Cambridge: MIT Press.

Papageorgiou, Y.Y., Smith, R.R. (1983), “Agglomeration as Local Instability of Spatially Uniform Steadt-States", Econometrica, 51, pp. 1109-19.

Rabenau, B.V. (1979), "Urban Growth with Agglomeration Economics and Diseconomics, Geographia Polonica, 42, pp. 77-90.

Richardson, B.V. (1973), Regional Growth Theory, New York: John Wiley.

Solow, R.M. (1973), "On Equilibrium Models of Urban Location”, in Essays in Modern Economics, edited by Parkin, M. London: Longman.

Solow, R.M., Vickrey, W.S. (1971), "Land Use in a Long Narrow City", Journal of Economic Theory, 3, pp. 430-47.

Stiglitz, J.E. (1967), "A Two Sector Two Class Model of Economic Growth", Review of Economic Studies, 34, pp. 227-38.

Uzawa, H. (1961), "On A Two-Sector Model of Economic Growth", Review of Economic Studies, 29, pp. 47-70.

Zabel, J.E. (2004), “The Demand for Housing Services", Journal of Housing Economics, 13, pp. 16-35.

Zhang, W.B. (1994), "Capital, Population and Urban Patterns", Regional Science and Urban Economics, 24, pp. 273-286.

Zhang, W.B. (2005), Economic Growth Theory, Hampshire: Ashgate.

Zhang, W.B. (2007), "Growth and Agglomeration of a Small-Open Multi-Regional Economy", The Journal of Economic Integration, 22, pp. 515-49.

Zhang, W.B. (2008a), International Trade Theory: Capital, Knowledge, Economic Structure, Money and Prices over Time and Space, Berlin: Springer.

Zhang, W.B. (2008b), Monetary Growth Theory: Money, Interest, Prices, Capital, Knowledge, and Economic Structure over Time and Space, London: Routledge. 